\title{
THE EXPECTED WeLl-BEING OF URBAN REFUGEES AND ASYLUM-SEEKERS IN JOHANNESBURG
}

\author{
Talita Greyling \\ Department of Economics and Econometrics, University of Johannesburg
}

Accepted: January 2016

\begin{abstract}
The influx of asylum-seekers and refugees from across Africa into democratic South Africa has increased significantly. The aim of this paper is to determine the factors that influences the expect well-being of this unique group. Expected well-being is an important determinant of both the decision to migrate and the choice of a country of destination. Knowledge about this determinant therefore informs refugee policies. The results show that only a few of the factors found in the literature explaining the expected well-being of voluntary migrants also explain the expected well-being of forced migrants. However, a number of factors found in the literature that explain the subjective well-being and well-being in general of refugees and asylum-seekers also went towards explaining the expected well-being of this group. These factors include: government assistance, culture, the time spent in South Africa, economic factors, crime, refugee status, reasons for leaving the home countries and the number of people staying in a house in the receiving country. The findings of this study emphasise the differences between forced and voluntary migrants and highlight the factors that influence the expected well-being of forced migrants. These in turn shed light on migration decisions and the choice of destination countries.
\end{abstract}

Key words: expected well-being, Johannesburg, forced migrants, refugees, Asylum-seekers, South Africa, well-being

JEL: D6, F23, J11, O15

\section{$1 \quad$ Introduction}

Since South Africa's transition to democracy, the influx into the country of asylum-seekers from across Africa has increased almost tenfold. The country has also become the largest recipient of individual applications for asylum in the world, with more than 207000 applications out of a total of 839000 globally (United Nations High Commissioner for Refugees, 2011). The majority of the refugees and asylum-seekers who move to South Africa find refuge in the bigger cities like Johannesburg. The influx of refugees and asylum-seekers into the cities has brought about new socio-economic challenges with the concomitant need for the development of policy measures to address them.

One of the major determinants of refugees' and asylum-seekers' migration decision and choice of destination country, insofar as they have a choice, is that of expected well-being (Massey, Arango, Hugo, Kouaouci, Pellegrino \& Taylor, 1993; Czaika, 2014; Spinks, 2013). Expected wellbeing can be defined as the anticipated level of a person's well-being and is related to the level of well-being s/he aspires to achieve (Czaika \& Vothknecht, 2012). Hence an understanding of the factors that influence expected well-being will not only contribute to a better understanding of the well-being of refugees and asylum-seekers, but will also lead to a better understanding of their decision to migrate as well as their choice of a destination country and region.

Research into the well-being of refugees and asylum-seekers has been limited and, to the best of the author's knowledge, no previous research on the determinants of the expected well-being of this group of people has been conducted internationally. However, studies on the factors and related matters that influence the expected well-being of voluntary migrants have been carried out (Valentina, Berg \& Vaaler, 2010; Czaika \& Vothknecht, 2012). There have also been studies on the determinants of well-being and subjective well-being ${ }^{1}$ of refugees and asylum-seekers that exclude any consideration of the 'expected' dimension of well-being. In this research we therefore 
address this gap in the literature by estimating the factors that influence the expected well-being of refugees and asylum-seekers residing in Johannesburg's inner city. For the purposes of this study, a data set collected by the Forced Migration Studies Programme (FMSP) (2006) on the inner city of Johannnesburg, which forms part of a larger project, the African City Project, is used. The study focuses on Johannesburg, as it has the highest concentration of foreign-born inner-city residents in South Africa. According to the Census 2001 data (Statistics South Africa (StatsSA), 2003), almost a quarter of the inner-city residents in Johannesburg were born outside South-Africa, compared to 10 per cent in Pretoria, 6 per cent in Durban and 4 per cent in Cape Town.

This research contributes to the refugee and asylum-seeker literature, as it adds to the knowledge on the factors that influence expected well-being, in turn shedding light on the decision to migrate and the choice of a destination country. A better understanding of these factors could contribute to informed policy responses.

The results of this study on the factors that have been found to influence the expected wellbeing of refugees and asylum-seekers show that only a few of them correspond to those found in the literature (see section 2) to explain the expected well-being of voluntary migrants. However, according to the literature reviewed here, there are a number of explanations for the well-being and subjective well-being ${ }^{1}$ of refugees and asylum-seekers that coincide with what is found in the study to explain the expected well-being of forced migrants. These factors relate mostly to the refugee status of the forced migrants, which gives them more certainty about their future, their living conditions and the support they will receive from government. These findings emphasise the differences between forced and voluntary migrants and also the differences between the factors that explain their expected well-being, which in turn influence their decision to migrate and their choice of a destination country.

In this paper, the definitions of refugees and asylum-seekers are adopted from the 1951 Convention Relating to the Status of Refugees and its 1967 Protocol. The Convention defines a refugee as: 'any person who, owing to a well-founded fear of being persecuted for reasons of race, religion, nationality, membership of a particular social group or political opinion, is outside the country of his/her nationality and is unable, or owing to such fear, is unwilling to avail himself/herself of the protection of that country. An asylum seeker is a person who is seeking protection as a refugee and is still waiting to have his/her claim assessed'. Refugees and asylumseekers are also referred to as 'forced migrants', as often they have no choice but to leave their home country to ensure their safety.

The remainder of this paper is structured as follows: section 2 contains a brief review of the literature on the determinants of expected well-being of voluntary migrants and the well-being in general of refugees and asylum-seekers. In section 3, there is a discussion on the data used in the analyses. Section 4 describes the methodology used, including the statistical techniques, the specification of the model and the selection of the variables. Section 5 contains a report on the results of the empirical analysis and the conclusions are drawn in section 6.

\section{Literature on the determinants of well-being}

In the introduction, it was pointed out that no previous research has been carried out internationally on the determinants of the expected well-being of refugees and asylum-seekers, therefore research related to the topic of the current study is reviewed. I divide the literature reviewed in two sections: in the first section, literature related to factors that influence the expected well-being of voluntary migrants is discussed. The second section explores the findings of the literature that investigates the general and subjective well-being of refugees and asylumseekers internationally and in studies relating to South Africa.

\subsection{Factors that influence the expected well-being of voluntary migrants}

The study by Czaika and Vothknecht (2012) is one of the only studies investigating the factors that influence the expected well-being of migrants. However, the study focuses on voluntary migrants 
rather than forced migrants, who are the focus of the current research paper.

In the study by Czaika and Vothknecht (2012), they used a longitudinal data set from the Indonesian Family Life Survey. The authors estimated an expected well-being function and included the following determinants: age, being male, level of education, hours worked, monthly income, community participation, being married, the age of the household head, household expenditure, households with farm income, households with non-farm income, female-headed households, number of adults in the household, number of children in the household, households with a TV set, household being rural, household's asset value and ethnic fractionalisation. They found that being over the age of 40 , being the household head and having more adults in the household to be statistically significant and negatively related to expected well-being. On the other hand, being married and having an education higher than junior high school was statistically significant and positively related to expected well-being. The other variables were found not to be statistically significant. In the current study, the author follows the example of Czaika \& Vothknecht (2012) and includes variables similar to those they included in their study on the estimated model (depending on the availability of data).

Czaika and Vothknecht (2012) omit to consider a fact that has been shown to be closely associated with the expected well-being of migrants, which is the region in which they live (Jurjevich \& Schrock, 2012; Faggian, Olfert \& Partridge, 2012). The expectations of future regional well-being is also a main consideration for the migrants in their choice of a destination country (Faggian et al., 2012). In the model estimated in this paper, the regional element of expected well-being is therefore incorporated into the model.

A further study which is related to the expected well-being of migrants, but which does not investigate the determinants of expected well-being, compares the distress levels and negative expectations of both voluntary and forced migrants residing in Norway (Valentina et al., 2010). The study is qualitative and includes 48 voluntary migrants and 45 forced migrants. The data was collected from 2005 to 2008. They found that forced migrants seem to incur greater distress and higher levels of negative expectations for the future than do voluntary migrants. This study reaffirms that it is likely that the expected well-being of forced migrants and voluntary migrants might differ.

\subsection{Factors influencing the general and subjective well-being of refugees and asylum-seekers}

Turning to international studies on the general well-being of refugees and asylum-seekers, the following emerged in studies undertaken in developed countries, including the USA, (Meredith, 1984; Tran \& Wright, 1986) and Australia (Colic-Peisker, 2009). The study by Meredith (1984) considered the subjective well-being of Lao Hmong refugees and asylum-seekers in Nebraska, while the study by Tran and Wright (1986) investigated the subjective well-being of Vietnamese refugees in the USA. Colic-Peisker (2009) investigated the subjective well-being of refugees from Bosnia and Herzegovina who had resettled in Australia. All the pre-mentioned studies showed that refugees and asylum-seekers were happier if they remained in contact with their families and attempted to reunite with them if they were able to speak the local language. Furthermore, a positive attitude from the people in the receiving country contributed to the refugees' and asylum-seekers' well-being (ColicPeisker, 2009; Meredith, 1984; Tran \& Wright, 1986). Acculturation and adaptation to the new environment, as well as social support, job satisfaction and financial satisfaction were all found to be significant contributors to refugees' well-being (Colic-Peisker, 2009).

In other international studies, further factors that influence the well-being of forced migrants are revealed. Correa-Velez, Gifford and Barnett (2010) studying refugees in Melbourne, Australia found that discrimination and social exclusion were some of the factors that impacted negatively on refugees' well-being. In a study in the Netherlands on Iranian refugees, Werkuyten and Nekuee (1999) found a positive relationship between the time spent in the host country and subjective well-being, implying that the longer refugees and asylum-seekers resided in a country, the higher their level of subjective well-being. In a study considering refugees from across the world, including Africa, the Balkans, Siberia, the Middle East and Southeast Asia, Krippner and McIntyre 
(2003) showed that refugees and asylum-seekers who leave their home countries because of persecution or civil war experience severe negative effects on their psychological well-being, which could lead to depression, anxiety and post-traumatic stress. Lastly, the positive effects of religion on subjective well-being were shown in the study by Connor and Koenig (2013), which considered data from the USA, Canada and Europe. In this study they found that, in areas like the USA, the attendance at religious meetings is positively related to occupational attainment, especially for second generation migrants (Connor \& Koenig, 2013). In this study, depending on the availability of data, these factors are built into the model to explain the expected well-being of forced migrants in Johannesburg.

To summarise, the factors found in the international literature that influence the subjective wellbeing of refugees and asylum-seekers are: maintaining contact with their families; speaking the receiving country's language; being received positively by the people in the receiving country; adaptation and acculturating to the new environment and the time spent in the host country.

In South Africa, no studies have been undertaken on the factors that influence the subjective well-being of refugees and asylum-seekers, although there have been studies related to the subject. The related studies include those on livelihood strategies, the rights and protection of refugees and asylum-seekers and xenophobia (see. among others, Landau, 2006; Jacobson, 2006; Crush \& Dodson, 2007; Neocosmos, 2008).

In considering livelihood strategies, Jacobson (2006) found that many of the refugees and asylum-seekers' livelihood strategies in South Africa were based on their economic, cultural and religious affiliations. Moreover, for refugees and asylum-seekers to enjoy a good quality of life, they needed access to protection, economic opportunities and social rights (Jacobson, 2006). In this study these factors are considered in the estimation of the expected well-being model.

On studies relating to xenophobia in South Africa, Neocosmos (2008) and Crush and Dodson (2007) found that South Africans had a negative attitude to foreigners and that such an attitude negatively affected the well-being of forced migrants. According to the research, the animosity originated in the belief that migrants took advantage of job opportunities and contributed to the increased crime rates in the country (Neocosmos, 2008; Crush \& Dodson, 2007).

Factors that have been found in South Africa to influence the well-being of refugees and asylum-seekers were economic, cultural and religious affiliations, crime and the ability to access protection, and economic and social rights.

In summary, the literature showed that the factors found to influence the expected well-being of migrants were age, education, relative income and marriage. In addition, the factors found internationally to influence the well-being and subjective well-being of refugees and asylumseekers were: maintaining contact with their families; speaking the receiving country's language; being received positively by the people in the receiving country; adaptation and acculturating to the new environment and the time spent in the host country. Factors that have been found in South Africa to influence the well-being of refugees and asylum-seekers were economic, cultural and religious affiliations, crime and the ability to access protection, and economic and social rights. In this paper, both the factors found to influence the expected well-being of voluntary migrants and those found to influence the well-being and subjective well-being of refugees and asylum-seekers, according to the literature, are included in the model to test the extent to which these factors explain the expected well-being of refugees and asylum-seekers in the inner city of Johannesburg.

\section{Data}

In the analysis, the researcher uses a data set collected by the FMSP in 2006, the 'Migration and the New African City' data set (FMSP, 2006). The survey was initially undertaken within the framework of the African Cities Project (ACP), the purpose of which was to collect comparative and longitudinal data on the migration patterns and the integration of migrants into their reception towns in southern, central and east Africa. The cities to be surveyed were selected on account of the high concentration of migrants in their inner cities. The cities included were: Johannesburg, 
Maputo, Nairobi and Lubumbashi. However, the project as a whole was never completed.

The survey conducted in the inner city of Johannesburg contains information on the demographic profile of the migrant, the conditions prevailing in the sending country before migration and the living conditions of the migrants after their arrival in South Africa. The data set is not a representative sample of all the migrants in South Africa or even of the migrants in Johannesburg, as only the inner city of Johannesburg, with its high concentration of migrants, was surveyed. However, the data provide an insight into the socio-economic circumstances of often difficult-to-reach populations.

An area cluster sampling technique was used for collecting the data. In preliminary consultative work, the suburbs in which the migrants reside were identified. The following suburbs in Johannesburg were included: Rosettenville, Mayfair, Fordsburg, Yeoville, Berea and Bertrams. The survey aimed to collect data from fixed quotas of migrant groups, divided among 600 nonnationals (Somali, Congolese and Mozambican) and a control group of 200 South Africans. The main characteristics of the respondents in the sample are shown in Table 1.

Table 1

Socio-economic and demographic characteristics (percentage of selected group, except if specified otherwise)

\begin{tabular}{|c|c|c|c|}
\hline & Forced Migrants & Voluntary Migrants & South Africans \\
\hline \multicolumn{4}{|l|}{ Characteristics } \\
\hline Number of respondents & 406 & 242 & 199 \\
\hline \multicolumn{4}{|l|}{ Sex } \\
\hline Male & 70 & 53 & 48 \\
\hline Female & 30 & 47 & 52 \\
\hline \multicolumn{4}{|l|}{ Age } \\
\hline $18-25$ years old & 20 & 22 & 35 \\
\hline $26-30$ years old & 28 & 30 & 18 \\
\hline $31-35$ years old & 27 & 18 & 12 \\
\hline $36-40$ years old & 16 & 15 & 11 \\
\hline $40+$ years old & 9 & 15 & 24 \\
\hline \multicolumn{4}{|l|}{ Marital status } \\
\hline Married/lived together & 54 & 44 & 41 \\
\hline Single & 46 & 56 & 59 \\
\hline \multicolumn{4}{|l|}{ Level of Education } \\
\hline Completed secondary school & 45 & 50 & 61 \\
\hline Completed tertiary training & 28 & 10 & 14 \\
\hline Master's degree or more & 3 & 2 & 1 \\
\hline \multicolumn{4}{|l|}{ Employment } \\
\hline Unemployed & 36 & 13 & 43 \\
\hline Employed full-time & 26 & 40 & 25 \\
\hline Employed part-time & 11 & 7 & 7 \\
\hline Casual employment & 20 & 16 & 15 \\
\hline Self-employed & 2 & .4 & 1 \\
\hline Voluntary worker & 2 & 1 & 1 \\
\hline Total employed & 61 & 64.4 & 49 \\
\hline \multicolumn{4}{|l|}{ Income } \\
\hline Mean annual income (Rand 2006) & 24319 & 25717 & 37711 \\
\hline
\end{tabular}

Source: Author's calculations of the Migration in the New African City Survey (Forced Migration Study Programme, 2006)

Among the total number of 847 respondents in the original sample, 406 were forced migrants, 242 were voluntary migrants and 199 were South Africans. The migrants in the sample were mainly men (63), while the male percentage among the forced migrants was even higher at 70 of the total 
forced migrant sample. Literature has shown that men are more likely to migrate than women are (Crush \& Dodson, 2007). This also applies to migrants in South Africa. One of the likely reasons that more men than women migrate to South Africa is the job opportunities offered to men, especially in the mining sector.

The majority of the migrants, including voluntary and forced migrants, are of working age, between the ages of 26 and 40 years. This underlines the notion that many migrants enter South Africa to find employment. The South African respondents included in the sample were slightly younger on average than the migrants, the majority aged between 18 and 25 .

More than half of the forced migrants (54 per cent) were married, although their spouses were not necessarily residing in South Africa. The proportion of married voluntary migrants to South Africans was slightly lower, at just over 40 per cent. This might be explained by the lower age of the previously mentioned groups.

A lower proportion of migrants (between 45 per cent and 50 per cent) compared to South Africans (61 per cent) indicated that they had completed secondary school. However, more than double the percentage of forced migrants had had tertiary training ( 28 per cent) compared to both voluntary migrants (10 per cent) and South Africans (14 per cent). A large proportion of the forced migrants could speak English (73 per cent) and 97 per cent could speak another South African language.

Approximately the same percentage of forced migrants (37 per cent) and South Africans (32 per cent) reported that they were employed in either the formal or the informal sector, compared to a much higher proportion of voluntary migrants (47 per cent) working in either of these sectors. This could possibly be explained by the fact that voluntary migrants probably secured employment before migrating to a receiving country. In a study by Mbatha and Roodt (2014) on migrants in South Africa, they showed that many of the migrants are entrepreneurs, who employ South African citizens. A fifth (20 per cent) of all the forced migrants indicated that they were in casual employment compared to 15 per cent of the South Africans and 16 per cent of the voluntary migrants. Considering the total percentage of employed respondents across the board in any type of employment, 61 per cent of all the refugees and asylum-seekers were employed compared to 64, 4 per cent of voluntary migrants and 49 per cent of the South African citizens.

The average income per capita per annum measured in Rands (for the year 2006) for the South Africans was much higher (R37 711) than the average income per capita per annum reported by either the forced migrants (R24 319) or the voluntary migrants (R25 717). The difference in income levels could be explained by the different types of employment (higher-skilled compared to lower-skilled) in the different groups. Furthermore, the higher income for South Africans could possibly also be ascribed to their receiving different types of social grants, which are added to their total income. The majority of international migrants do not receive these grants (Jacobson, 2006).

Most of the forced migrants ( 45 per cent) in the sample were residing in apartments, which they shared with more than one family, compared to voluntary migrants and South Africans, who mostly lived in apartments occupied by single families.

Approximately 20 per cent of the forced migrants in the sample had been in South Africa for less than one year, 40 per cent between one and four years (entering South Africa after 2002), and only 5 per cent in South Africa for a time period of longer than 10 years. The significantly higher proportion of migrants in the sample, who had entered South Africa since 2002 can be explained by, inter alia, the unstable conditions which prevailed in the DRC and Somalia.

As the focus of this paper is on forced migrants, the researcher selected only the respondents who were either asylum-seekers or refugees for inclusion in the empirical analysis. After adjustment for missing data, the sample size was 279 adult respondents.

\section{Methodology}

In this section both the model specification and the estimation techniques are described. Further, the method of construction of the dependent variable, that is, expected well-being, and the selection of the explanatory variables used in the analysis are discussed. 


\subsection{Model specification and estimation techniques}

The specifications of the expected well-being model were based on previous studies conducted on both the expected well-being (Czaika \& Vothknecht, 2012) and the well-being literature (see, for example Posel \& Casale, 2011; Knight \& Gunatilaka, 2010). The specification of the expected well-being function is as follows:

$$
E W_{i}=\beta_{0}+\beta_{m} X_{m i}+u_{i}
$$

where $E W_{i}$ represents expected well-being, $\beta_{0}$ is the constant, $\beta_{m}$ provides the coefficients that indicate the relative importance of different contributors to expected well-being, $X_{m i}$ is a vector of $m$ explanatory socio-economic variables of $i(i=1 \ldots n)$ respondents, and $u_{i}$ is an error term including all the factors that were not captured in the well-being equation.

In most of the well-being literature, especially the subjective well-being studies, Ordinary Least Squares (OLS) and ordered probit are used as estimation techniques (see Posel \& Casale, 2011; MacKerron, 2012; Bartram, 2013; Blaauw \& Pretorius, 2013). Ordered probit is an estimation technique appropriate for estimations using categorical data in which the distribution of the variables are, in all likelihood, not normal. However, in research by Ferrer-i-Carbonell and Frijters (2004) and Stevenson and Wolfers (2009), it was shown that negligible differences existed between the results obtained from the aforementioned methods and that the signs and significance of the estimated coefficients in these studies were similar. Furthermore, although the results of the different regression methodologies in larger samples were found to be comparable, in their analyses of cross-sectional data and smaller samples (McFadden, 1994) with the absence of panel data, researchers found that OLS regressions were more reliable than ordered probit estimates. An advantage of OLS estimations as opposed to ordered probit estimations is the directness of the interpretation of the estimated coefficients (see MacKerron, 2012; Bartram, 2013; Blaauw \& Pretorius, 2013).

However, the OLS estimation technique has certain limitations when it comes to estimating models that suffer from endogeneity, as the error term and the explanatory variables become correlated and result in potentially biased estimated regression coefficients. To determine whether endogeneity is present in the estimated model, the researcher made use of Instrumental Variables Regressions (IVR), which control for unobserved heterogeneity. Following this, post estimation endogeneity tests are conducted to confirm or deny the presence of endogeneity in the estimated model. To estimate the IVR, the two stage least square estimation technique is used.

In this research, depending on the outcome of the post estimation tests of endogeneity, the researcher follows the customary methods used by earlier researchers in the well-being literature (Czaika \& Vothknecht, 2012; MacKerron, 2012; Bartram, 2013; Blaauw \& Pretorius, 2013) and uses OLS (or in the event of endogeneity, IVR) and ordered probit estimation techniques. All the diagnostic tests are performed on the estimated regressions to determine whether the regressions fulfil the set assumptions of the specific estimation technique.

\subsection{The derived expected well-being variable}

In the Migration in the New African City Survey (FMSP, 2006), two questions were identified, which were then used to derive an expected well-being variable. The two questions were: 'Generally speaking, do you think your life will be better or worse than your parents' lives?' and 'Where do you expect to be living two years from now?' The first question captures expected individual well-being, whereas the second question refers to the preference for a specific region, thus regional well-being, which is an important dimension of the total expected well-being (Dasgupta, 2004; Lora \& Powell, 2011; Faggian. Olfert \& Partridge, 2012). The derived variable gives an all-encompassing measure of expected well-being, which informs both the migration decision and the choice of destination country.

To derive the expected well-being variable, the researcher allocated scores to the responses to the two identified questions. The first question had three response categories. These were: 'My life will be better than my parents' lives', 'It will be the same as my parents' lives', or 'It will be 
worse than my parents' lives'. Scores between three ('My life will be better') and one ('My life will be worse') were allocated to each response.

The second question was recoded so that it had two response categories. The allocation of the scores was informed by the findings by Cernea and McDowell (2000) and Faggian et al. (2012). These findings showed that, if the refugees and asylum-seekers preferred to stay in the host country, this reflected expected 'regional well-being' (Faggian et al., 2012). However, if they wished to move to a third country, this reflected negative expectations of the region, thus affecting regional wellbeing negatively. Therefore, responses to the second question indicating that the refugees and asylum-seekers would expect to live in the city where they were, or another place in South Africa, scored three (the maximum score). The score of three was allocated to the question so that the two questions included in the derived expected well-being variable had equal weighting. If the respondent indicated that $\mathrm{s} /$ he expected to move to a third country, it was assumed that the resettlement was not successful and negatively affected the person's expected well-being; half of the maximum score (a score of 1.5) was allocated to this response.

The expected well-being variable was derived by summing the scores of the responses of the two questions of each respondent in a way similar to the methods used in the social sciences to sum the items of a scale (Pallant, 2007). For example, if a refugee or asylum-seeker felt that his/her life would be worse than the parents' lives (a score of one) and s/he would prefer to leave South Africa (a score of 1.5), the summed score would be 2.5 (see Table 2). A score of six was achieved if a refugee or asylum seeker thought that his/her life would be better than the parents' lives and they would prefer to stay in South Africa. The scores reflect a certain order of expected well-being, with 2.5 being the lowest and 6 the highest. These scores were recoded from one to six, to reflect the order of expected well-being (see Table 2), the ordered variable was used in further analyses. Table 2 shows the frequencies and percentages of the expected well-being variable.

Table 2

The frequencies of the expected well-being variable

\begin{tabular}{|c|c|c|c|c|}
\hline Score & Code & Frequency & Percentage & $\begin{array}{c}\text { Cumulative } \\
\text { percentage }\end{array}$ \\
\hline 2.5 & 1 & 11 & 3.3 & 3.4 \\
\hline 3.5 & 2 & 3 & 0.9 & 4.2 \\
\hline 4.0 & 3 & 16 & 4.8 & 9.1 \\
\hline 4.5 & 4 & 105 & 31.8 & 40.9 \\
\hline 5.0 & 5 & 14 & 4.2 & 45.2 \\
\hline 6.0 & 6 & 181 & 54.8 & 100.0 \\
\hline
\end{tabular}

Source: Author's calculations of the Migration in the New African City Survey (Forced Migration Study Programme, 2006)

The majority of the refugees and asylum-seekers' expected well-being was at a level of either four ( 31.8 per cent) or six ( 54.8 per cent). A level four indicates that the respondent felt that his/her life would be better than their parents' lives, though they would prefer not to stay in South Africa. A level six indicated that the migrant expected that his/her life would be better than the parents' lives, and s/he would prefer to stay in South Africa. Judging from these results, most of the refugees and asylum-seekers in this sample were positive about their expected well-being and the majority (63.8 per cent) would most likely, if circumstances permitted, settle in South Africa (FMSP, 2006). This finding concurs with the findings by Valentina et al. (2010), showing that refugees and asylum-seekers generally have positive expectations about their future well-being. Furthermore, Myroniuk and Vearey (2014), in their research specific to Johannesburg, found that foreign-born migrants' livelihood outcomes compared well to those of South African citizens.

\subsection{The proposed explanatory variables}

The selection of the explanatory variables to describe the expected well-being function of refugees and asylum-seekers was based on the availability of data and the reviewed literature on the 
expected well-being of migrants, as well as the well-being and subjective well-being of refugees and asylum-seekers (see section 2). Factors such as 'refugee status', which were hypothesised as possibly influencing the 'expected well-being' of refugees and asylum-seekers, were also included.

The researcher recoded all the nominal variables to dummy variables so that the variables took a value of either 1 or 0 . The selected variables, with explanations about the coding and descriptive statistics, are shown in Table 3. The selected variables are: 'age', 'victim of crime', 'education', 'gender', 'type of housing', 'married', 'religion', 'relative income', 'employment', 'income', 'government assistance', 'culture', 'religion', 'time in South Africa', 'number of people in the house', 'reason for leaving country', 'refugee status' and an interaction variable 'education x employment'. The interaction variable was included as an independent variable, as the researcher wanted to investigate whether employment has different effects on expected well-being depending on the level of education of the forced migrants. Research has shown that education and employment are closely related (Teichler \& Kehm, 1995). However, in studies on forced refugees, it has been found that they are often under-employed, which might have a different effect on expected wellbeing than being employed, according to specific skills levels (Cornwell \& Inder, 2004).

Table 3

Explanatory variables included in the model

\begin{tabular}{|c|c|c|c|c|c|c|}
\hline Variable & Categories/ description & $\begin{array}{l}\text { Type of } \\
\text { variable }\end{array}$ & Coding & Min & Max & Mean \\
\hline Gender & $\begin{array}{l}\text { Male } \\
\text { Female }\end{array}$ & Dummy & $\begin{array}{l}1 \\
0\end{array}$ & 0 & 1 & .695 \\
\hline Type of housing & $\begin{array}{l}\text { House/Apartment } \\
\text { Hostel Dormitory/Informal }\end{array}$ & Dummy & $\begin{array}{l}1 \\
0\end{array}$ & 0 & 1 & .037 \\
\hline Married & $\begin{array}{l}\text { Married } \\
\text { Single }\end{array}$ & Dummy & $\begin{array}{l}1 \\
0\end{array}$ & 0 & 1 & .537 \\
\hline Religion & $\begin{array}{l}\text { With a religion } \\
\text { No religion }\end{array}$ & Dummy & $\begin{array}{l}1 \\
0\end{array}$ & 0 & 1 & .985 \\
\hline Crime & $\begin{array}{l}\text { Has been a victim of crime } \\
\text { Has not been a victim of crime }\end{array}$ & Dummy & $\begin{array}{l}1 \\
0\end{array}$ & 0 & 1 & .590 \\
\hline Relative income & $\begin{array}{l}\text { Poorer than others in area where you live } \\
\text { About the same or better off than others in } \\
\text { the area where you live }\end{array}$ & & 0 & 0 & 1 & 0.69 \\
\hline Employment & $\begin{array}{l}\text { Employed } \\
\text { Unemployed }\end{array}$ & Dummy & $\begin{array}{l}1 \\
0\end{array}$ & 0 & 1 & .563 \\
\hline Government assistance & $\begin{array}{l}\text { Helps } \\
\text { Never Helps }\end{array}$ & Dummy & $\begin{array}{l}1 \\
0\end{array}$ & 0 & 1 & \\
\hline Refugee status & $\begin{array}{l}\text { Yes } \\
\text { No }\end{array}$ & Dummy & $\begin{array}{l}1 \\
0\end{array}$ & 0 & 1 & .478 \\
\hline Reason for leaving country & $\begin{array}{l}\text { Escape war and persecution } \\
\text { Economic, education and other }\end{array}$ & Dummy & $\begin{array}{l}1 \\
0\end{array}$ & 0 & 1 & .573 \\
\hline Culture & $\begin{array}{l}\text { Better for society if immigrants maintain } \\
\text { their customs } \\
\text { Better for society if immigrants adopt the } \\
\text { customs of the host country }\end{array}$ & Dummy & 0 & 0 & 1 & .836 \\
\hline Education & Years of education & Continuous & - & 0 & 18 & 11.26 \\
\hline Age & Age in year & Continuous & & 22 & 63 & 31.51 \\
\hline Time in RSA & Number of months residing in South Africa & Continuous & - & 1 & 15 & 8.042 \\
\hline $\begin{array}{l}\text { Number of people in the } \\
\text { house }\end{array}$ & $\begin{array}{l}\text { Number of people living in a single } \\
\text { structure }\end{array}$ & Continuous & - & 0 & 30 & 6.462 \\
\hline Income & Average income per week & Continuous & - & 0 & 2500 & 523.65 \\
\hline Employment $x$ Education & Interaction variable & Continuous & & 0 & 18 & 10.12 \\
\hline
\end{tabular}

Source: Author's calculations of the Migration in the New African City Survey (Forced Migration Study Programme, 2006)

The results of the estimated model are discussed in the next section. 


\section{Results}

In the results section, the researcher discusses the findings on possible endogeneity in the estimated model, which is followed by a discussion of the results of the OLS and the ordered probit models.

\subsection{Results on the tests of endogeneity}

As endogeneity is often a challenge in the social sciences, when people's behaviour is estimated. The researcher first uses IVR to test whether endogeneity is present in the current estimated model. Potential endogeneity is likely to spread from the variable 'time spent in South Africa', as this variable might include an unobservable element of experiences by refugees and migrants while staying in the country. Although these experiences are unobserved, they might potentially have an influence on the expected well-being of forced migrants. The data set has limited capability for providing instrumental variables. However, 'how often refugees and asylum-seekers change residence' was identified as a potential instrument for the variable indicating the time forced migrants spent in South Africa ('time in South Africa'), which might be endogenous. The suggested instrument is correlated with the 'time in South Africa' variable $(r=.547)$. After running the IVR using two-stage least squares and conducting the post-estimations tests for endogeneity, the following was found: the Durbin score $=2.772(p=0.096)$ and the Wu-Hausman score $=2.651(p=$ $0.1044)$. Based on these results the researcher could not reject the null hypothesis stating that the variables are exogenous. Thus in the absence of endogeneity OLS was used together with ordered probit to estimate the model set out in section 4.1. The results are shown in Table 4.

\subsection{Results on the estimated OLS and ordered probit models}

The estimated model showed that the F-statistic (OLS estimation) and the Wald chi-squared statistic (ordered probit estimation) were statistically significant, indicating that the explanatory variables were jointly significant in explaining the variation in the expected well-being variable. The OLS model's R squared value (0.132) and the ordered probit model Pseudo R squared value (0.190) were consistent with the results obtained in similar cross-sectional well-being studies (Powdthavee, 2003; Ebrahim, Botha and Snowball, 2013).

Table 4

Results on the determinants of expected well-being

\begin{tabular}{|l|c|c|}
\hline \multicolumn{2}{|l|}{} & \multicolumn{2}{l|}{ OLS } & $0.043(0.096)^{\star}$ \\
\hline Explanatory Variables & $0.032(0.065)^{\star}$ & $-0.185(0.247)^{\star}$ \\
\hline Crime & $-0.093(0.166)^{\star}$ & $0.508(0239)$ \\
\hline Education & $0.368(0.161)$ & $0.391(0.299)$ \\
\hline Gender & $0.243(0.203)$ & $0.612(0.377)$ \\
\hline Type of housing & $0.177(0.243)$ & $0.760(0.258)$ \\
\hline Married & $0.509(0.173)$ & $1.085(0.898)$ \\
\hline Religion & $0.681(0.589)$ & $0.354(0.195)^{\star}$ \\
\hline Relative income & $0.245(0.132)^{\star}$ & $2.134(1.015)^{\star *}$ \\
\hline Employment & $1.677(0.681)^{\star *}$ & $0.044(0.082)$ \\
\hline Income & $0.055(0.053)$ & $0.335(0.194)^{\star}$ \\
\hline Government assistance & $0.177(0.128)^{\star}$ & $-0.666(0.305)^{\star \star *}$ \\
\hline Employment $x$ Education & $-0.489(0.204)^{\star *}$ & $0.082(0.287)^{\star *}$ \\
\hline Refugee status & $0.006(0.194)^{\star \star}$ & $0.246(0.314)^{\star *}$ \\
\hline Culture & $0.134(0.214)^{\star * *}$ & $-0.042(0.026)^{\star}$ \\
\hline Number of people in the house & $-0.030(0.018)^{\star}$ & \\
\hline
\end{tabular}




\begin{tabular}{|l|c|c|}
\hline \multicolumn{2}{|c|}{ OLS } & Ordered probit \\
\hline Explanatory Variables & $-0.034(0.029)^{\star \star}$ & $-0.070(0.043)^{\star \star}$ \\
\hline Time in South Africa & $-0.575(0.169)^{\star}$ & $-0.877(0.257)^{\star *}$ \\
\hline Reason for leaving country & 271 & 271 \\
\hline N & 0.132 & 0.190 \\
\hline Adjusted R / Pseudo R 2 & $3.406^{\star \star *}$ & $1641.80^{\star \star *}$ \\
\hline F-Statistic / Wald Chi-square & \\
\hline
\end{tabular}

Source: Author's calculations of the Migration in the New African City Survey (Forced Migration Study Programme, 2006) Notes: (1) Dependant variable = expected well-being. (2) Standard errors are in parentheses.

*** Significant at the 1 percent level ** Significant at the 5 percent level * Significant at the 10 percent level.

The results for the signs and the significance of the estimated coefficients of the two estimation techniques (OLS and ordered probit) were similar, in line with the findings by Ferrer-i-Carbonell and Frijters (2004) and Stevenson and Wolfers (2009). The only differences noted were in the level of the statistical significance in the variables 'employment $\mathrm{x}$ education' and 'culture', which varied between 5 per cent and 10 per cent in the models.

As explained in the methodological section, the researcher interpreted the OLS estimated coefficients owing to the advantage of direct interpretability of OLS estimations over probit estimations (Blaauw \& Pretorius, 2013).

The results of the model showed the majority of the included explanatory variables to be statistically significant, although not all of these revealed the expected signs. The initial discussion will be on those variables included in the model estimation based on the variables that were found in the literature to explain the expected well-being of voluntary migrants: 'age', 'relative income', 'education' and 'marriage' and thereafter the remaining variables.

The 'age' variable was found to be statistically significant and was positively related to the expected well-being of the refugees and asylum-seekers. The positive relationship shows that, as the age of refugees and asylum-seekers increases, their expected well-being also increases. It is likely that, as refugees and asylum-seekers grow older, and keeping in mind that the respondents are aged between 22 and 63 years, their job opportunities and housing circumstances also improve, and this positively influences their expected well-being. The study by Czaika and Vothknecht (2012) on the relationship between age and the expected well-being of voluntary migrants revealed similar results.

The 'relative income' variable was statistically significant and was positively related to the expected well-being variable. However, the 'income' variable was not statistically significant. This finding supports the arguments by Alpizar, Carlsson and Johansson-Stenman (2002) and Frey and Stutzer (2002) in the subjective well-being literature, that people's relative income position in society is a better measure of well-being than absolute income levels. Therefore, it can be argued that, if refugees and asylum-seekers believe that their relative income is the same or better than their neighbours' income, it positively influences their expected well-being.

'Education' was found not to be statistically significant in explaining the expected well-being of refugees and asylum-seekers, although the sign was positive. A likely reason for this result is that higher levels of education among refugees and asylum-seekers do not necessarily lead to improved well-being. This result partly accords with the findings of Czaika and Vothknecht (2012). Their results showed that lower levels of education do not explain the expected well-being of voluntary migrants, although higher levels of education are statistically significant in explaining the expected well-being of forced migrants in the USA, which is a developed country.

'Married' was found not to be statistically significant. This finding does not match that of Czaika and Vothknecht (2012) on the expected well-being of voluntary migrants, or the studies by Diener and Seligman (2004), Blanchflower and Oswald (2003) and Mahadea (2013) on subjective well-being. According to these studies, marriage suggests companionship and the sharing of burdens and, for this reason, it increases both expected well-being and well-being. A possible explanation for the marriage variable not being statistically significant is that marriage might 
increase the spouses' burdens, as they have to take responsibility not only for themselves, but also for their spouse. Furthermore, if a spouse remains in the original country, the partner in the host country would probably be concerned about the well-being of the one left behind in the original country, which negatively affects their psychological well-being. Such factors seem to outweigh any positive effects of marriage on the expected well-being of refugees and asylum-seekers.

Secondly, the researcher considered the variables included in the model based on those variables found to explain the well-being or subjective well-being of refugees and asylum-seekers. The majority of these variables were found to be statistically significant, including: 'victim of crime', 'gender', 'type of housing', 'employment', 'government assistance', 'time in South Africa', 'reason for leaving the country', 'culture' and 'number of people in the house'. The variables found not to be statistically significant, and which were included in the model based on the factors that explained the well-being of forced migrants, were 'gender', 'type of housing' and 'religion'.

The 'victim of crime' variable was found to be negatively related to expected well-being, and was statistically significant, indicating that higher levels of crime negatively influenced the expected well-being of the sample group. The study by Partridge (2013) on internal migrants in South Africa supports this finding. The study found that, post-migration, the migrants reported being exposed more frequently to a variety of crime-related factors influencing their levels of wellbeing negatively.

Being male was related positively to expected well-being, although the 'gender' variable was not statistically significant. This finding corresponds to the finding by Czaika and Vothknecht (2012) on migrants and the study by Hinks and Gruen (2007) on the well-being of South Africans, showing that gender does not affect expected well-being.

The 'type of housing', which was shown to influence the positive attitude on the part of migrants in the research by Silveira and Ebrahim (1998), was found not to be statistically significant in explaining the expected well-being of refugees and asylum-seekers, indicating that residing in houses, apartments, hostels or informal dwellings does not influence their expected well-being. It is likely that the type of housing is not statistically significant, as housing for refugees and asylum-seekers in South Africa is often of only of a temporary nature and the possibility of moving to a better type of housing in the future plays a greater role in determining expected well-being than their current type of housing. The research on forced migrants in South Africa shows that refugees and asylum-seekers have limited rights and protection in South Africa. When they arrive in the country, and in cities such as Johannesburg, they often stay in derelict buildings, where they seek shelter in overcrowded conditions, often sharing their accommodation with other families (Peberdy \& Majodina, 2000; Jacobson, 2006).

The literature on refugees and asylum-seekers showed that religious affiliation contributes to their livelihood strategies (Jacobson, 2006). It has also been shown that religion predicts people's subjective well-being. However, in this study the variable 'religion' indicates only whether an individual follows a religion or not, but it does not reflect the type of religion with which a respondent is affiliated. 'Religion' in this study was found to be statistically not significant, although it was positively related to the expected well-being variable. This finding of statistically not significant might reflect the different nuances of subjective well-being and expected well-being. Subjective well-being reflects life satisfaction, whereas expected well-being is related to the level of well-being a person aspires to achieving (Czaika \& Vothknecht, 2012). It is possible that forced migrants do not view the fact that they are religious as predictive of the level of well-being they anticipate in the future. If future studies control for the type of religion, this result might be different, especially if the type of religion either corresponds to (possibly a positive effect) or differs from (possible a negative effect) that of the local population. When the variable was excluded, the explanatory power of the model decreased, showing that religion does have an impact on the specification of the model; for this reason the researcher decided to retain the variable.

'Employment' was found to be statistically significant. The estimated coefficient of the employment variable is relatively large and, if the other coefficients of the explanatory variables are kept constant, then being employed as opposed to not being employed, leads to an 
improvement of the well-being variable of 1.67 units. This emphasises the importance of being employed in predicting the expected well-being of forced migrants. Being employed is a means of economic survival for refugees and asylum-seekers, who have very little additional resources on which to rely, or government assistance to carry them through difficult times (Peberdy, Crush \& Msibi, 2004). A large proportion (61 per cent) of the refugees and asylum-seekers in the sample found employment in either the formal or informal sector or as casual workers, even though research by Porter, Hampshire, Mashiri, Dube \& Maponya (2010) showed that migrants are exposed to economic and political exclusion. This reflects their urgency and need to find employment. The finding of urgency for migrants to find jobs was confirmed in the studies by Cornwell and Inder (2004), which showed that, despite the theory suggesting that migrants should have higher unemployment rates than non-migrants, the opposite is true, owing to the migrants' motivation and drive to find jobs.

The interaction variable 'employment $\mathrm{x}$ education' was statistically significant and negatively related to the expected well-being variable. If a person was unemployed, the interaction variable had a value of zero and if they were employed the interaction variable had a value equal to the respondent's years of education. It was found that the employment of people with more years of education was negatively related to the expected well-being variable. This finding is counterintuitive, although it agrees with findings by Witte and Kalleberg (1995), which show that people are often employed outside their field of training. In this study, the negative relationship could possibly be explained by refugees and asylum-seekers often being severely under-employed; for example, a medical doctor is employed as a security guard. A similar finding of underemployment was found in a study by Blaauw, Pretorius, Schoeman and Schenk (2012) relating to Zimbabwean day-labourers in South Africa. They showed that Zimbabwean migrants, although they had relatively high levels of schooling and spoke and understood English well, often entered the job market at lower skills levels in positions such as day labourers. The same results were shown in the study by Cornwell and Inder (2004) regarding the under-employment of migrants in South Africa. This situation might contribute to frustration on the part of refugees and asylumseekers, which could contribute to lower levels of expected well-being.

As expected, the variable 'number of people in the house' was statistically significant in terms of a negative relationship with expected well-being. Since 'the number of people in the house' might be an indication of forced migrants' living conditions, as well as possibly reflecting the dependency ratio, it is likely that a higher number of people staying in a specific house would negatively influence expected well-being.

Previous studies found that integration, referring to both maintaining one's own ethnic culture and adopting characteristics of the host country's culture, had the best psychological outcomes for refugees (Werkuyten \& Nekuee, 1999). In this research, the survey question, whether the respondents thought it was better for a society of migrants to maintain their customs and cultures than to adopt the customs and cultures of the host country, was statistically significant and positively related to the expected well-being variable. This finding concurs partly with that by Werkuyten and Nekuee (1999), who found that it contributed to the well-being of forced migrants if they maintained their own customs and cultures, although the survey question did not require the respondents' opinion on adopting the host country's customs and cultures.

The research by Werkuyten and Nekuee (1999) on Iranian refugees in the Netherlands established a positive relationship between the time spent in a host country and well-being. The researchers found the variable to be statistically significant, although negatively related to the expected well-being variable. This implied that the longer the time period refugees and asylumseekers spent in South Africa, the lower their level of expected well-being would be. A possible explanation is that, when refugees and asylum-seekers arrive in South Africa, they initially have relatively high expectations, but they are disappointed when their expectations are not realised. Although almost a third of the forced migrants reported finding employment in South Africa (see Table 1), the type of employment is often low-income employment and not what they expected. Furthermore, they receive limited government support and are often exposed to hostile behaviour 
from South Africans.

The variable 'government assistance', which is the support received from government, contributed positively to expected well-being. Any support for refugees and asylum-seekers in fulfilling their basic needs contributed positively to their expected well-being, while lack of government support, especially on their arrival, contributed to their suffering (Jacobson, 2006).

The variable 'reason for leaving country' was found to be statistically significant and negatively related to expected well-being. In a study by Krippner and McIntyre (2003), they found that refugees and asylum-seekers leaving their home countries as a result of persecution or civil war could have severe negative effects on their psychological well-being and could lead to depression, anxiety and post-traumatic stress. The psychological effects of forced migration can also have future implications for psychological well-being and influence expected well-being negatively.

Lastly, the variable 'refugee status', indicating having been accepted as a refugee, was statistically significant and positively related to expected well-being. This positive relationship can be explained by the fact that forced migrants with refugee status have more certainty about their future in the host country. 'Refugee status' also gives the group some protection and certain additional rights.

To conclude, very few of the variables found in the literature to explain the expected well-being of voluntary migrants also explained the expected well-being of refugees and asylum-seekers. The variables that coincided were 'age' and 'relative income'. However, a number of factors found in the literature to explain the subjective well-being or well-being of forced migrants also explained their expectations (expected well-being) regarding their future well-being in South Africa. Included in these are: factors related to government assistance, culture, the time spent in South Africa, economic factors, crime, refugee status, and the reasons for leaving their home countries and the number of people in the house. The results of this study show that there are differences between the factors that influence the expected well-being of voluntary migrants, as revealed in the reviewed literature (see section 2), and the factors that influence the expected well-being of forced migrants. Thus, when analysing the migration decisions of forced migrants based on their expected well-being, different factors should be considered from those used in the analyses of voluntary migrants.

\section{Conclusion}

The number of refugees and asylum-seekers migrating to Johannesburg, the economic centre of Africa, is increasing substantially from year to year. Knowledge of the migration decision and choice of destination country by forced migrants is therefore essential. Information on these topics can be gained by investigating an important determinant of these decisions, expected well-being. At an empirical level it is valuable to investigate the determinants of expected the well-being of refugees and asylum-seekers, as this informs policy and guides future developments.

This paper examined the factors explaining the expected well-being of refugees and asylumseekers. As no previous research has been carried out on this topic, the explanatory variables included in the model were based on results found in research on the expected well-being of voluntary migrants and on the factors found to influence the subjective well-being and well-being of refugees and asylum-seekers.

For the purposes of the study a data set on the Migration in the New African Cities (FMSP, 2006) was used. The researcher derived the dependent variable expected well-being by equally weighting and summing two variables representing expected well-being and expected regional well-being, representing an all-encompassing variable.

It was found that very few of the variables explaining the expected well-being of voluntary migrants, as shown in the literature, also explained the expected well-being of forced migrants, as revealed in this study. The explanatory variables that voluntary migrants and forced migrants had in common were: 'age' and 'relative income'. However, many of the variables that explained the subjective well-being and well-being of forced migrants, as shown in the literature, were also 
found in this study to explain the expected well-being of this group. The variables found to explain the expected well-being of forced migrants include: 'government assistance', 'refugee status', 'time in South Africa', 'the interaction variable 'employment $\mathrm{x}$ education', 'reason/s for leaving their country', 'culture' (the opinion that it is better for society for migrants to retain their own culture), and the 'number of people in the house'. The findings of this study emphasise the uniqueness of forced migrants as a group of people.

When analysing the migration decisions of forced migrants based on their expected well-being, the factors found to explain the concept in this study should be considered. Knowledge of these factors also contributes to understanding of the choice of destination country of forced migrants. The choice of the destination country is of importance to all policy makers. South Africa has been the main destination country for refugees and asylum-seekers in Africa for the last two decades. Policy-makers ought to recognise this and adapt policy measures accordingly. The rights of refugees and asylum-seekers should be protected, and better housing should be made available to forced migrants. Policy-makers should take cognisance of the important contribution forced migrants could make to the skills base in South Africa. Furthermore, based on the increasing number of xenophobic attacks in South Africa, government should have stricter control over the inflow of forced migrants as well as their movements on entering and settling in the country; both to control illegal inflows and protect forced migrants from bodily harm

Future research based on longitudinal data is needed to enhance knowledge on the migration decisions of forced migrants.

Endnote:

1 Subjective well-being refers to the subjective measurement of well-being, using a question such as 'Are you satisfied with your life?' In this research the term 'well-being' also includes the concept of 'subjective well-being'.

\section{Acknowledgements:}

We would like to thank Economic Research Southern Africa (ERSA) for their financial support and the FMSP for access to their data.

\section{References}

ALPIZAR, F., CARLSSON, F. \& JOHANSSON-STENMAN, O. 2002. How much do we care about absolute versus relative income and consumption? Essays on Environmental Policy-Making in Developing Countries: Applications to Costa Rica. ALPÍZAR, F.R. (ed.) Sweden: Department of Economics: Göteborg University, 3.1-3.27.

BARTRAM, D. 2013. Migration, return and happiness in Romania. European Societies, 15(3):408-422.

BLAAUW, D. \& PRETORIUS, A. 2013. The determinants of subjective well-being in South Africa - an exploratory enquiry. Journal of Economic and Financial Sciences, 6(1):179-194.

BLAAUW, P., PRETORIUS, A., SCHOEMAN, C. \& SCHENCK, R. 2012. Explaining migrant wages: The case of Zimbabwean day labourers in South Africa. International Business \& Economics Research Journal, 11(12):1333-1346.

BLANCHFLOWER, D. \& OSWALD, A. 2003. Does inequality reduce happiness? Evidence from the States of the USA from the 1970s to the 1990s. Mimeographed. Warwick University.

CERNEA, M. \& MCDOWELL, C. (eds.) 2000. Risks and reconstruction: Experiences of resettlers and refugees. World Bank Publications. Washington DC.

COLIC-PEISKER, V. 2009. Visibility, settlement success and life satisfaction in three refugee communities in Australia. Ethnicities, 9(2):175-199.

CONNOR, P. \& KOENIG, M. 2013. Bridges and barriers: Religion and immigrant occupational attainment across integration contexts. International Migration Review, 47(1):3-38.

CORNWELL, K. \& INDER, B. 2004. Migration and unemployment in South Africa: When motivation surpasses the theory (No. 2/04). Available at: www.csae.ox.ac.uk/conferences/2004-GPRaHDiA/papers/5fCornwell-CSAE-2004.pdfM [accessed September 2012]. 
CORREA-VELEZ, I., GIFFORD, S.M. \& BARNETT, A.G. 2010. Longing to belong: Social inclusion and well-being among youth with refugee backgrounds in the first three years in Melbourne, Australia. Social Science Med, 71(8):1399-408.

CRUSH, J. \& DODSON, B. 2007. Another lost decade: The failures of South Africa's post-apartheid migration policy. The Royal Dutch Geographical Society, 98(4):436-454.

CZAIKA, M. 2014. Migration and economic prospects. Journal of Ethnic and Migration Studies, Ahead of print:1-25.

CZAIKA, M. \& VOTHKNECHT, M. 2012. Migration as cause and consequence of aspirations. University of Oxford IMI Working Paper 57. International Migration Institute.

DASGUPTA, P. 2004. Human well-being and the natural environment. Oxford: Oxford University Press. DIENER, E. \& SELIGMAN, M. 2004. Towards an economy of well-being. Psychological Science in the Public Interest, 5(1):1-31.

EBRAHIM, A., BOTHA, F. \& SNOWBALL, J. 2013. Determinants of life satisfaction among race groups in South Africa. Development Southern Africa, 30(2):168-188.

FAGGIAN, A., OLFERT, M.R. \& PARTRIDGE, M.D. 2012. Inferring regional well-being from individual revealed preferences: The 'voting with your feet approach'. Cambridge Journal of Regions, Economy and Society, 5(1):163-180.

FERRER-I-CARBONELL, A. \& FRIJTERS, P. 2004. How important is methodology for the estimates of the determinants of happiness? Economic Journal, Royal Economic Society, 114(497):641-659.

FORCED MIGRATION STUDY PROGRAMME (FMSP). 2006. Migration and the new African city (nonnationals): Survey.

FREY, B. \& STUTZER, A. 2002 Happiness and economics: How the economy and institutions affect human well-being. Princeton: Princeton University Press.

HINKS, T. \& GRUEN, C. 2007. What is the structure of South African happiness equations? Evidence from quality of life surveys. Social Indicators Research, 82(2):311-336.

JACOBSON, K. 2006. Refugees and asylum-seekers in urban areas: A livelihood perspective. Journal of Refugee Studies, 19(3):273-286.

JURJEVICH, J.R. \& SCHROCK, G. 2012. Is Portland really the place where young people go to retire? Migration patterns of Portland's young and college-educated, 1980-2010. Metropolitan Knowledge Network (MKN) article. Sept. 2012.

KNIGHT, J. \& GUNATILAKA, R. 2010. Great expectations? The subjective well-being of rural urban migrants in China. World Development, 38(1):113-124.

KRIPPNER, S. \& MCINTYRE, T.M. (eds.) 2003. In the wake of war. The psychological impact of war trauma on civilians: An international perspective. Portsmouth: Greenwood Publishing Group.

LANDAU, L.B., 2006. Protection and Dignity in Johannesburg: Shortcomings of South Africa's Urban Refugee Policy. Journal of Refugee Studies, 19(3):308-327.

LORA, E. \& POWELL, A. 2011. A new way of monitoring the quality of urban life (No. 2011, 12) Working paper. World Institute for Development Economics Research.

MACKERRON, G. 2012. Happiness economics from 35,000 feet. Journal of Economic Survey, 26(4): 705-735.

MAHADEA, D. 2013. On the economics of happiness: The influence of income and non-income factors on happiness. South African Journal of Economic and Management Sciences, 16(1):39-51.

MASSEY, D.S., ARANGO, J., HUGO, G., KOUAOUCI, A., PELlEGRINO, A. \& TAYLOR, J.E. 1993. Theoretical international migration: A review and appraisal. Population and Development Review, 19(3): 431-466.

MBATHA, C.N. \& ROODT, J. 2014. Recent internal migration and labour market outcomes: Exploring the 2008 and 2010 national income dynamics study (NIDS) panel data in South Africa. South African Journal of Economic and Management Sciences, 17(5):653-672.

MCFADDEN, D. 1994. Econometric analysis of qualitative response models. Handbook of Econometrics. GTILICHES, R. \& INTRILIGATOR, A. (eds.) New York: Elsevier Science Publishers.

MEREDITH, W.H. 1984. Level and correlates of perceived quality of life for Lao among refugees in Nebraska. Social Indicators Research, 14(1):83-97. 
MYRONIUK, T.W. \& VEAREY, J. 2014. Social capital and livelihoods in Johannesburg: Differential advantages and unexpected outcomes among foreign-born migrants, internal migrants and long-term South African residents. International Migration Review, 48(1):243-273.

NEOCOSMOS, N. 2008. The politics of fear and fear of politics: Reflections on xenophobic violence in South Africa. Journal of Asian and African Studies, 43(6):588-589.

PALLANT, J. 2007. SPSS survival manual: A step-by-step guide to data analysis using SPSS version 15. Nova Iorque: McGraw Hill.

PARTRIDGE, A. 2013. Rural-urban migration and subjective well-being: The South African experience. Unpublished MCom dissertation. Department of Economics. University of Cape Town.

PEBERDY, S., CRUSH, J. \& MSIBI, N. 2004. Migrants in the City of Johannesburg: A report for the City of Johannesburg. Southern African Migration Project, Johannesburg.

PEBERDY, S. \& MAJODINA, Z. 2000. Just a roof over my head? Urban Forum, 11(2):273-288.

Netherlands: Springer.

PORTER, G., HAMPSHIRE, K., MASHIRI, M., DUBE, S. \& MAPONYA, G. 2010. 'Youthscapes' and escapes in rural Africa: Education, mobility and livelihood trajectories for young people in Eastern Cape, South Africa. Journal of International Development, 22:1090-1101.

POSEL, D.R. \& CASALE, D.M. 2011. Relative standing and subjective well-being in South Africa: The role of perceptions, expectations and income mobility. Social Indicators Research, 104(2):195-223.

POWDTHAVEE, N. 2003. Is the structure of happiness equations the same in poor and rich countries? The case of South Africa. Warwick Economic Research Papers.

SILVEIRA, E.R. \& EBRAHIM, S. 1998. Social determinants of psychiatric morbidity and well-being in immigrant elders and whites in East London. Journal of Geriatric Psychiatry, 13(11):801-812.

SPINKS, H. 2013. Destination anywhere? Factors affecting asylum-seekers' choice of destination country. Parliament of Australia: Department of Parliamentary Services: Research Paper no. 1.

STATISTICS SOUTH AFRICA (StatsSA). 2003. Census 2001: Census in brief. Available at: www.statssa.gov.za/census/census_2001/census_in_brief/CIB2001.pdf [accessed February 2013].

STEVENSON, B. \& WOLFERS, J. 2009. The paradox of declining female happiness. American Economic Journal: Economic Policy, 1(2):190-225.

TEICHLER, U. \& KEHM, B.M. 1995. Towards a new understanding of the relationships between higher education and employment. European Journal of Education, 30(2):115-132.

TRAN, T.V. \& WRIGHT JR., R. 1986. Social support and subjective well-being among Vietnamese Refugees. The Social Service Review, 60(3):449-459.

UNITED NATIONS HIGH COMMISSIONER FOR REFUGEES (UNHCR). 2011. Country operations profile - South Africa. Available at: www.unhcr.org/pages/49e485aa6.html [accessed 2012-03-12].

VALENTINA, C.I., BERG, J.E. \& VAALER, A.E. 2010. Expectations of the future: Immigrant, asylumseeker, or refugee - does it matter? Journal of Psychiatric Intensive Care, 6(1):23-30.

WERKUYTEN, M. \& NEKUEE, S. 1999. Subjective well-being, discrimination and cultural conflict: Iranians living in the Netherlands. Social Indicators Research, 47(3):281-306.

WITTE, J.C. \& KALLEBERG, A.L. 1995. Matching training and jobs: The fit between vocational education and employment in the German labour market. European Sociological Review, 11(3):293-317. 